\title{
Serial tumour markers serum carcinoembryonic antigen and cancer antigen 15-3 assays in detecting symptomatic metastasis in breast cancer patients
}

\author{
A. Bahrami, ${ }^{1}$ M. R. Mortazavizadeh, ${ }^{2}$ M.F. Yazdi ${ }^{2}$ and M. Chamani ${ }^{3}$
}

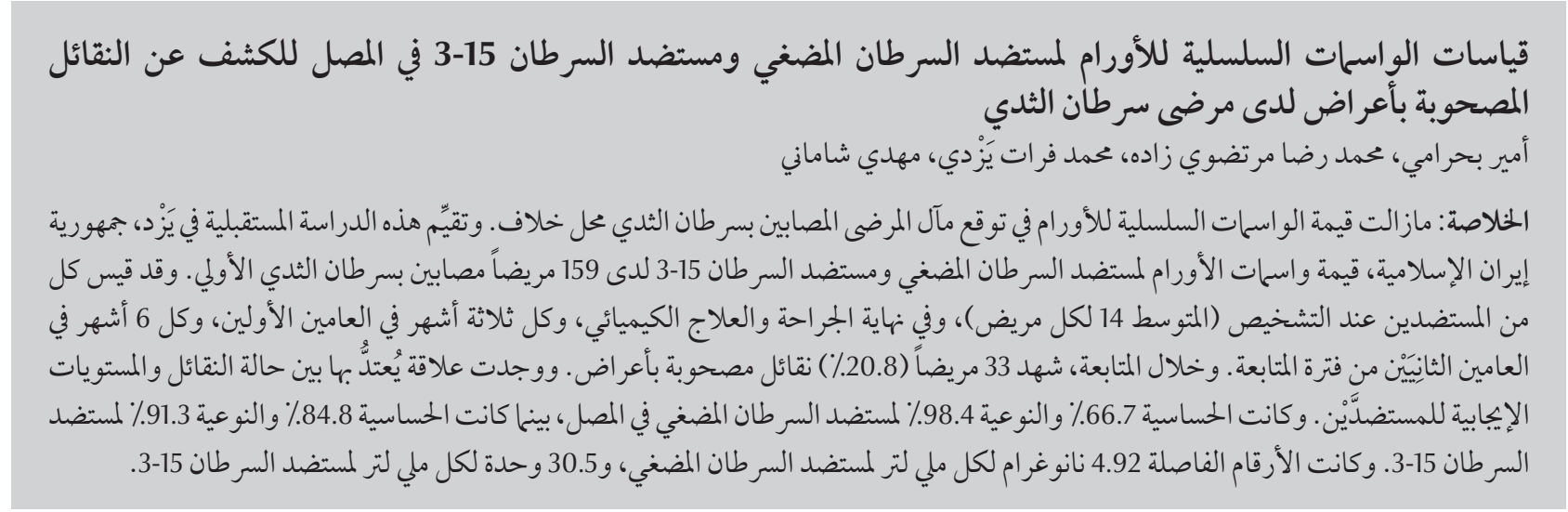

ABSTRACT The value of serum tumour markers in the prognosis of patients with breast cancer is controversial. This prospective study in Yazd, Islamic Republic of Iran, assessed the value of the tumour markers carcinoembryonic antigen (CEA) and cancer antigen (CA) 15-3 in 159 patients with primary breast cancer. CEA and CA15-3 assays (mean 14 per patient) were performed at diagnosis, end of surgery and chemotherapy and every 3 months in the first 2 years and every 6 months in second 2 years of the follow-up period. During follow-up, 33 patients (20.8\%) presented symptomatic metastasis. A significant relationship was seen between metastasis status and positive CEA and CA15-3 levels. The sensitivity and specificity were $66.7 \%$ and $98.4 \%$ for CEA respectively and $84.8 \%$ and $91.3 \%$ for CA15-3 respectively. Optimum cut-offs were $4.95 \mathrm{ng} / \mathrm{mL}$ and $30.5 \mathrm{U} / \mathrm{mL}$ for CEA and CA15-3 respectively.

Dosages systématiques des marqueurs tumoraux tels que I'antigène carcino-embryonnaire sérique et I'antigène carbohydrate 15-3 dans le dépistage de métastases symptomatiques chez des patientes atteintes d'un cancer du sein

RÉSUMÉ La valeur des marqueurs tumoraux sériques dans le pronostic des patientes atteintes d'un cancer du sein est controversée. La présente étude prospective à Yazd (République islamique d'Iran) a évalué la valeur des marqueurs tumoraux tels que l'antigène carcino-embryonaire et l'antigène carbohydrate 15-3 chez 159 patientes ayant reçu un premier diagnostic de cancer du sein. Les dosages de l'antigène carcino-embryonaire et de l'antigène carbohydrate 15-3 (moyenne 14 par patiente) ont été réalisés lors du diagnostic, après la chirurgie et la chimiothérapie puis tous les trois mois au cours des deux premières années et tous les 6 mois dans les deux années suivantes pendant la période de suivi. Pendant le suivi, 33 patientes (20,8\%) ont présenté des métastases symptomatiques. Un lien significatif a été observé entre le statut métastasique et les taux positifs pour l'antigène carcino-embryonaire et l'antigène carbohydrate 15-3. La sensibilité et la spécificité étaient de 66,7\% et 98,4\% pour l'antigène carcino-embryonaire respectivement et de $84,8 \%$ et $91,3 \%$ respectivement pour l'antigène carbohydrate 15-3. Les valeurs seuils optimales étaient de 4,95 ng/ml et 30,5 U/ml pour l'antigène carcinoembryonaire et l'antigène carbohydrate $15-3$ respectivement. 


\section{Introduction}

Carcinoembryonic antigen (CEA) was one of the first serum-based tumour markers to be characterized, and its utility has been assessed in a variety of malignancies including breast cancer [1-3]. The results of serum CEA assay can reflect prognosis in primary breast cancer patients, with elevated levels reflecting adverse outcomes $[3,4]$. Several studies have shown that changes in the CEA serum level might be linked to progression or regression status in breast cancer patients [5-8].

It should be noted that most of these studies were performed nearly 15 years ago. Since the discovery of the serum cancer antigen (CA)-15.3 marker, the use of CEA for determining prognosis of patients with breast cancer has declined. Some studies have suggested that serum CEA is not even useful as a routine assay due to its low sensitivity in breast cancer patients in comparison with CA15-3 [9-13]. Nevertheless, CEA is still one of the most widely used blood tests for monitoring breast cancer patients.

Due to limited health budgets coupled with the increasing price of health care services, developing countries need to select effective and suitable tumour markers among the various available markers for the management protocols for patients with breast cancer. The present study reports the results of 4 years of followup of patients with primary breast cancer in Yazd, Islamic Republic of Iran between 2000 and 2006. The study was performed to evaluate the usefulness of the serial assessment of serum CEA and CA15-3 for prediction of symptomatic metastasis in primary breast cancer patients. Other useful markers (oestrogen receptors, progesterone receptors, CerB2 and P53 tumour markers) were included for comparison.

\section{Methods}

\section{Sample and study design}

The study sample was women with primary breast cancer attending a private clinic in Yazd, Islamic Republic of Iran. The inclusion criteria were non-smoker females with primary breast cancer, without signs or symptoms of metastasis or recurrence and with no other malignant disorders. We excluded patients who had other disorders that could affect the serum level of CEA or CA15-3, whether oncological (lung, colorectal, pancreas and ovarian cancer) or non-oncological (endometriosis, pelvic inflammation, hepatitis, cirrhosis, peptic ulcer, colitis and diverticulitis). The women were followed up for a 4-year period between July 2002 and August 2006. There were 168 patients who met our inclusion criteria but 9 patients discontinued their follow-up visits due to migration to other regions. Thus 159 patients participated in the study.

The study was approved by the ethics research committee of Shahid Sadoughi University of Medical Sciences and Health Services and all the patients gave their informed consent to participate.

\section{Data collection}

\section{Clinical data}

The tumour size and number of outbreak lymph nodes were recorded for each woman. Laboratory assays were performed for all participants at the first study visit to determine expression levels of oestrogen and progesterone receptors and the tumour markers CerB2 and P53. Chest X-rays, bone scans and liver ultrasonography were performed for all study participants at the beginning of the study and patients with metastases at the start were excluded. Blood samples were taken and clinical examinations were performed in the time of diagnosis, end of surgery, end of chemotherapy and every 3 months in the first 2 years and every 6 months in the second 2 years of follow-up. Imaging studies including chest X-rays, liver ultrasonography and bone scans were performed if there was clinical or laboratory (abnormal serum levels of CEA or CA15-3) suspicion of symptomatic metastasis.

\section{Tumour markers assays}

In the present study CEA and CA15-3 levels were measured from patients' serum sample. A total of 2226 determinations of serum CEA and CA15-3 (mean 14 per patient) were performed. CEA and CA15-3 were determined by a commercial immunoradiometric assay (Abbott Laboratories and CIS International). If elevated serum levels of CEA or CA15-3 were observed in the follow-up period, a separate sample was obtained for confirmation of CEA or CA15-3 elevation. CEA was considered elevated when levels $>5 \mathrm{ng} /$ $\mathrm{mL}$ were detected in 2 sequential determinations. Elevations of CEA above these values were considered as false positive if no symptomatic metastasis was diagnosed in the following physical examination or imaging after the determination. The same pattern was considered for serum CA15-3 levels, which were considered as elevated at levels $>31 \mathrm{U} / \mathrm{mL}$.

Only CEA and CA15-3 were assessed serially; the other markers were assessed once, at the beginning of the study. Oestrogen receptors, progesterone receptors, CerB2 and P53 tumour markers were determined by a receptor assay method. Oestrogen receptor assay levels $>5 \mathrm{fmol} / \mathrm{mg}$ and progesterone receptor assay levels > $15 \mathrm{fmol} / \mathrm{mg}$ of cytosolic protein were considered as positive. CerB2 and P53 results were scored positive or negative.

\section{Statistical analysis}

We used SPSS, version 16.0 and the chi-squared and Student $t$-tests 
for statistical analysis. Two-tailed $P$-values $<0.05$ were considered as significant. We divided study participants at the end of the follow-up time according to their clinical status (with or without symptomatic metastasis) and this classification was used as gold standard for determination of sensitivity and specificity of study tumour markers. Sensitivity was calculated as: (number of metastatic patients whose tumour marker levels were elevated/ total number of metastatic patients) $\times 100$. Specificity was calculated as: (number of non-metastatic patients with normal tumour marker values/ total number of non-metastatic patients) $\times 100$.

\section{ROC curve calculation}

During the 4-year follow-up period, we checked serum levels of CEA and CA15-3 14 times and for calculation of sensitivity and specificity of these antigens we used their highest serum values before metastasis in metastatic patients or the highest values during the whole follow-up time for nonmetastatic patients. The areas under the receiver operating characteristic (ROC) curve were calculated as a measure of predictive discrimination of tumour response and progression by CEA and CA15-3 variation. An index of 0.5 indicated no discrimination ability, whereas a value of 1 indicated perfect discrimination. The cut-off points for elevated levels of the markers were identified according to the corresponding plotted curves. The difference between proportions was evaluated by the chi-squared test with Yates' correction when necessary.

\section{Results}

A total of 159 patients with primary breast cancer participated in the study. The mean age of the women was 48.8 (SD 10.7) years, range 22-78 years. The mean size of tumours was 1.94 (SD 0.70$) \mathrm{cm}$, range $22-78 \mathrm{~cm}$. An average of 2.86 (SD 4.30) lymph nodes were involved, range $0-8$. At the beginning of the study, 50 patients (31.4\%) were positive for CrbB2, 54 (34.0\%) for P53, 73 (45.9\%) for progesterone receptors and 83 (52.2\%) for oestrogen receptors.

The mean CEA and CA15-3 values in participants at the time of diagnosis were 1.69 (SD 0.99) ng/mL and 18.9 (SD 7.2) $\mathrm{U} / \mathrm{mL}$ respectively. After 6 months chemotherapy, there was a significant increase in CEA level to $1.87(\mathrm{SD} 1.05) \mathrm{ng} / \mathrm{mL}(P=0.01)$ and non-significant increase in CA15-3 level to $20.1(\mathrm{SD} 10.0) \mathrm{U} / \mathrm{mL}(P=0.08)$ (Table 1).

During the follow-up period, 33 (20.8\%) of our patients presented symptomatic metastasis. A positive CEA value was found in 18 metastatic patients (54.5\%) and CA15-3 was positive in 30 metastatic patients (90.9\%).

A significant relationship was found between positive serum CEA and CA15-3 levels and metastasis status $(P=0.001)$. However, there was no relationship between serum CEA and CA15-3 positivity and expression of oestrogen and progesterone receptors or tumour markers CerB2 and P53 (Table 2).

\section{ROC curve analysis}

According to the traditional cut-off points, we calculated the sensitivity and specificity as $66.7 \%$ and $98.4 \%$ respectively for CEA and $84.8 \%$ and 91.3\% respectively for CA15-3. According to these data, the positive likelihood ratios for CEA and CA15-3 were 41.7 and 9.8 respectively.

For ROC curve analysis, we considered the highest values of tumour markers before metastasis in metastatic patients and the highest values during the whole follow-up period for others patients. According to our ROC curves, we determined that the highest sensitivity and specificity cutoff points for positive results were 4.95 $\mathrm{ng} / \mathrm{mL}$ for CEA and $30.5 \mathrm{U} / \mathrm{mL}$ for CA15-3 (Figure 1).

\section{Discussion}

The results of our prospective study demonstrate that CEA tumour marker had lower sensitivity than CA15-3 for prediction of metastasis in the follow-up monitoring of primary breast cancer patients after surgery ( $66.7 \%$ versus $84.8 \%)$. The optimum cut-off points were 4.95 $\mathrm{ng} / \mathrm{mL}$ for CEA and $30.5 \mathrm{U} / \mathrm{mL}$ for CA15-3.

We found a significant elevation in CEA levels after 6-months followup and a non-significant increase in CA15-3. In a number of published

\begin{tabular}{|c|c|c|c|c|}
\hline \multirow[t]{2}{*}{ Period } & \multicolumn{2}{|c|}{ CEA (ng/mL) } & \multicolumn{2}{|c|}{ CA15-3 (U/mL) } \\
\hline & Mean (SD) & Range & Mean (SD) & Range \\
\hline At diagnosis & $1.69(0.99)$ & $0.1-4.9$ & $18.9(7.2)$ & $2-40$ \\
\hline After 6 months & $1.87(1.05)$ & $0.2-5.2$ & $20.1(10.0)$ & $5-85$ \\
\hline$P$-value & 0.01 & & 0.08 & \\
\hline
\end{tabular}

$S D=$ standard deviation. 


\begin{tabular}{|c|c|c|c|c|c|}
\hline Variable & No. of cases & $\begin{array}{c}\mathrm{CEA}^{\mathrm{a}}(\mathrm{ng} / \mathrm{mL}) \\
\operatorname{Mean}(\mathrm{SD})\end{array}$ & $P$-value & $\begin{array}{c}\mathrm{CA}_{15-3^{\mathrm{a}}(\mathrm{U} / \mathrm{mL})} \\
\text { Mean }(\mathrm{SD})\end{array}$ & $P$-value \\
\hline \multicolumn{6}{|l|}{ CrbB2 } \\
\hline $\begin{array}{l}\text { Negative } \\
\text { Positive }\end{array}$ & $\begin{array}{r}109 \\
50\end{array}$ & $\begin{array}{l}3.75(2.13) \\
4.18(2.86)\end{array}$ & 0.27 & $\begin{array}{l}32.4(19.9) \\
33.8(20.1)\end{array}$ & 0.68 \\
\hline \multicolumn{6}{|l|}{ P53 } \\
\hline $\begin{array}{l}\text { Negative } \\
\text { Positive }\end{array}$ & $\begin{array}{r}105 \\
54\end{array}$ & $\begin{array}{l}3.93(2.42) \\
3.79(2.33)\end{array}$ & 0.73 & $\begin{array}{l}31.3(17.8) \\
25.8(23.4)\end{array}$ & 0.18 \\
\hline \multicolumn{6}{|c|}{ Progesterone receptors } \\
\hline $\begin{array}{l}\text { Negative } \\
\text { Positive }\end{array}$ & $\begin{array}{l}86 \\
73\end{array}$ & $\begin{array}{l}3.95(2.30) \\
3.70(2.49)\end{array}$ & 0.68 & $\begin{array}{l}32.9(21.8) \\
32.7(17.6)\end{array}$ & 0.96 \\
\hline \multicolumn{6}{|c|}{ Oestrogen receptors } \\
\hline $\begin{array}{l}\text { Negative } \\
\text { Positive }\end{array}$ & $\begin{array}{l}76 \\
83\end{array}$ & $\begin{array}{l}3.81(2.33) \\
3.96(2.45)\end{array}$ & 0.70 & $\begin{array}{l}32.7(17.3) \\
32.9(22.2)\end{array}$ & 0.97 \\
\hline \multicolumn{6}{|l|}{ Metastasis } \\
\hline $\begin{array}{l}\text { No } \\
\text { Yes }\end{array}$ & $\begin{array}{r}126 \\
33\end{array}$ & $\begin{array}{l}3.25(1.38) \\
6.30(3.62)\end{array}$ & $<0.001$ & $\begin{array}{l}27.6(13.5) \\
52.7(27.1)\end{array}$ & $<0.001$ \\
\hline
\end{tabular}

${ }^{a}$ Using the highest CEA and CA75-3 value before metastasis for metastatic patients and during all checkups for non-metastatic patients. $S D=$ standard deviation .

studies elevated levels of both serum tumour markers CEA and CA15-3 were found during follow-up of breast cancer patients [14-24]. Although some tumour markers cause over- or under-estimation of disease progress, CA 15-3 was directly correlated with disease extent in our study. This contradicts the study of Bon et al. who reported that CA15-3 had no relation with disease stage in breast cancer patients [24]. This may have been because of the small number of cases from each clinical stage that they evaluated in their study. As a

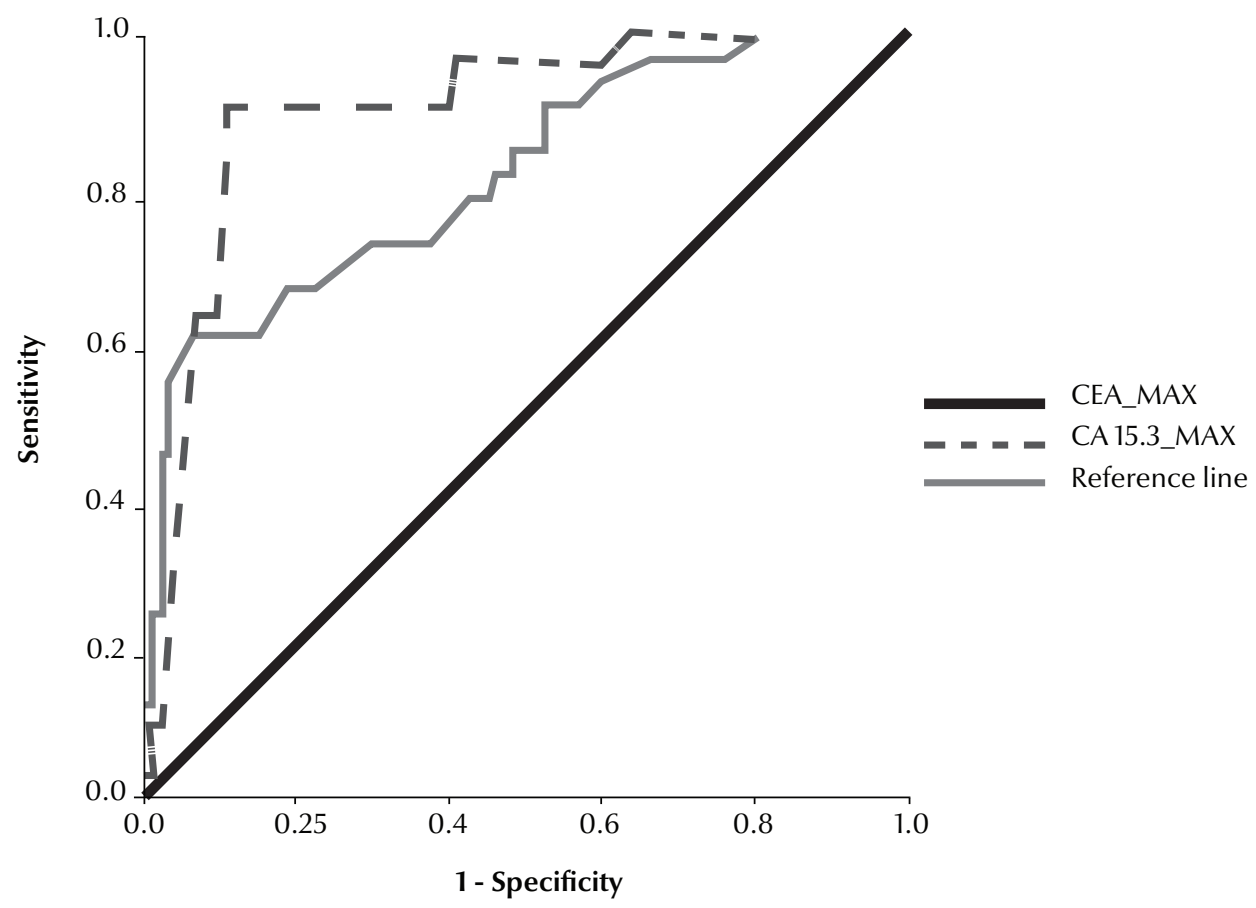

Figure 1 Receiver operating characteristic curve and comparison of tumour markers carcinoembryonic antigen (CEA) and cancer antigen (CA) 15-3 levels in patients with symptomatic metastasis $(n=33)$ 
rule, increases in tumour markers in a particular analyte are not absolute evidence for the presence of malignancy or metastasis, and the physician must consider this finding within the overall context of patient management.

The clinical efficacy of tumour markers assays in monitoring of breast cancer patients has been doubted due to their low sensitivity in primary breast cancer patients $[25,26]$ and at the present time we cannot conclusively assess the clinical impact of CA15-3 in the monitoring and management of breast cancer patients. According the American Society of Clinical Oncology clinical guidelines for use of serum tumour markers in breast cancer patients, there is insufficient evidence to recommend serum tumour markers in routine monitoring of breast cancer patients [25]. Nevertheless, among the various cancer markers, CA15-3 is generally considered to be the most suitable single marker, followed by CEA [14], and our study confirms the higher predictive value of CA15-3. Nevertheless, we must focus our use of tumour markers on patients' survival and quality of life. In the absence of effective treatment modalities for metastatic breast cancer patients, detection or prediction of breast cancer metastasis may not improve patient survival.

\section{Acknowledgements}

The authors wish to acknowledge from Dr Ahmad Reza Shamshri for his help in data analysis and manuscript preparation.

\section{References}

1. Carcinoembryonic antigen: its role as a marker in the management of cancer. A National Institutes of Health Consensus Development Conference. Annals of Internal Medicine, 1981, 94:407-409.

2. Sikorska H, Shuster J, Gold P. Clinical applications of carcinoembryonic antigen. Cancer Detection and Prevention, 1988, 12(1-6):321-355.

3. Lang BA et al. Three-year follow-up of carcinoembryonal antigen levels in the serum of patients with breast cancer. Neoplasma, 1984, 31:79-87.

4. Gaglia P et al. Prognostic value of CEA and ferritin assay in breast cancer: a multivariate analysis. European Journal of Cancer and Clinical Oncology, 1988, 24:1151-1155.

5. Tormey DC et al. Biological markers in breast carcinoma. III. Clinical correlations with carcinoembryonic antigen. Cancer, 1977, 39:2397-2404.

6. Falkson $\mathrm{HC}$ et al. Carcinoembryonic antigen in patients with breast cancer: an adjunctive tool to monitor response and therapy. Cancer, 1978, 42:1308-1313.

7. Lokich JJ, Zamcheck N, Lowenstein MW. Sequential carcinoembryonic antigen levels in the therapy of metastatic breast cancer: a predictor and monitor of response and relapse. $A n$ nals of Internal Medicine, 1978, 89:902-906.

8. Mughal AW et al. Serial plasma carcinoembryonic antigen measurements during treatment of metastatic breast cancer. Journal of the American Medical Association, 1983, 249:18811886.

9. Safi $\mathrm{F}$ et al. The value of the tumor marker CA 15-3 in diagnosing and monitoring breast cancer. A comparative study with carcinoembryonic antigen. Cancer, 1991, 68:574-582.

10. Fletcher RH. Carcinoembryonic antigen. Annals of Internal Medicine, 1986, 104:66-73.

11. Loprinzi CL et al. Prospective evaluation of carcinoembryonic antigen levels and alternating chemotherapeutic regimens in metastatic breast cancer. Journal of Clinical Oncology, 1986, 4:46-56.

12. Tondini $\mathrm{C}$ et al. Comparison of CA15-3 and carcinoembryonic antigen in monitoring the clinical course of patients with metastatic breast cancer. Cancer Research, 1988, 48:4107-4112.

13. Colomer R, Ruibal A, Salvador L. Circulating tumor marker levels in advanced breast carcinoma correlate with the extent of metastatic disease. Cancer, 1989, 64:1674-1681.
14. Lamerz R, Stieber P, Fateh-Moghadam A. Serum marker combinations in human breast cancer (review). In Vivo, 1993, 7(6B):607-613.

15. Colomer R et al. Circulating CA 15-3 levels in the postsurgical follow-up of breast cancer patients and in non-malignant diseases. Breast Cancer Research and Treatment, 1989, 13:123-133.

16. Crippa F et al. Single determination of CA15-3 and bone scintigraphy in the diagnosis of skeletal metastases of breast cancer. Journal of Nuclear Biology and Medicine, 1992, 36:52-55.

17. Dixon AR et al. Epithelial mucin core antigen (EMCA) in assessing therapeutic response in advanced breast cancer-a comparison with CA15.3. British Journal of Cancer, 1993, 68:947-949.

18. Dnistrian AM et al. Evaluation of CA M26, CA M29, CA 15-3 and CEA as circulating tumor markers in breast cancer patients. Tumour Biology, 1991, 12:82-90.

19. Miserez AR et al. Clinical value of a mucin-like carcinoma-associated antigen in monitoring breast cancer patients in comparison with CA 15-3. European Journal of Cancer, 1991, 27:126-131.

20. Molina R et al. MCA in patients with breast cancer: correlation with CEA and CA15-3. International Journal of Biological Markers, 1990, 5:14-21.

21. Molina $\mathrm{R}$ et al. Use of serial carcinoembryonic antigen and CA 15.3 assays in detecting relapses in breast cancer patients. Breast Cancer Research and Treatment, 1995, 36:41-48.

22. Safi $\mathrm{F}$ et al. Comparison of CA 15-3 and CEA in diagnosis and monitoring of breast cancer. International Journal of Biological Markers, 1989, 4:207-214.

23. Sölétormos $\mathrm{G}$ et al. A novel method for monitoring high-risk breast cancer with tumor markers: CA 15.3 compared to CEA and TPA. Annals of Oncology, 1993, 4:861-869.

24. Bon GG et al. Clinical and technical evaluation of ACS BR serum assay of $\mathrm{MUC1}$ gene-derived glycoprotein in breast cancer, and comparison with CA 15-3 assays. Clinical Chemistry, 1997, 43:585-593.

25. Clinical practice guidelines for the use of tumor markers in breast and colorectal cancer. Adopted on May 17, 1996 by the American Society of Clinical Oncology. Journal of Clinical Oncology, 1996, 14:2843-2877.

26. American Society of Clinical Oncology. 1997 update of recommendations for the use of hematopoietic colony-stimulating factors: evidence-based, clinical practice guidelines. Journal of Clinical Oncology, 1997, 15:3288. 